\title{
The Research on the Change of the Cost of Labor Migration in Urban and Rural Areas and Enterprise Labour Shortage
}

\author{
Ma Jing* \\ The economy and trade Department \\ Xijing University \\ Xi'an, China \\ mj3293452@me.com
}

\author{
Wu Aidong \\ The economy and trade Department \\ Xijing University \\ Xi'an, China \\ 359371150@qq.com
}

\begin{abstract}
As for our country enterprise in the process of transformation in the development of changes in the cost of Labor migration, put forward the effective countermeasures for the enterprises in solving the difficult labor shortage problem. This article uses the theory of cost-benefit analysis method and figuer1.1and figure1.2 to analyze the problem of the change of the cost of labor migration in urban and rural areas. In the context of increasing the cost of urban and rural labor migration, the comprehensive solution of labor shortage should be from the government, labor companies, and workers. As there are many reasons in China's labor shortage, the thoughts of solving the problem should also be considered from many aspects, multi-pronged approach to solve the problem: The perspective of the government, enterprises, and workers.
\end{abstract}

Keywords-Cost of Labor Migration; Enterprise Labor Shortage; Theory of Cost-Benefit; Scale of the Labor Flow; Marginal Cost

\section{CHANGES IN THE COST OF LABOR MIGRATION IN URBAN AND RURAL AREAS}

Labor mobility is the performance of the market mechanism to play a role in the allocation of resources. Since the reform and opening-up, China's labor flow is not only speeding up, the size is increasing, but the flow is also showing a complex situation. ${ }^{[1]} \mathrm{A}$ large number of labor flows between the provinces, urban and rural areas, between cities, between urban and rural areas, and the flow of labor force is gradually increasing abroad.

Wherever Times is specified, Times Roman or Times New Roman may be used. If neither is available on your word processor, please use the font closest in appearance to Times. Avoid using bit-mapped fonts if possible. True-Type 1 or Open Type fonts are preferred. Please embed symbol fonts, as well, for math, etc.

\section{A. The Marginal Cost and the Total Cost Increase} with the Expansion of the Scale of the Labor Flow.

According to the theory of Cost-benefit, the economic flow of population is the process of people's pursuit of greater economic benefit and the moving people will obtain mort profit. Seeing from the individual point of view, the implementation of process flow cost includes the cost of money and non-monetary cost. The former includes a flow cost, mainly referring to transportation costs, housing moving costs, policy fees applying for license fees, information cost in looking for jobs, the decrease of profit due to unemployment during flow, and lose of pension; nonmonetary costs are mainly including two parts, one is about labor transfer time cost (spend a lot of time in flowing and finding new jobs) and the abandon of assets in specific location (such as qualifications, customers, leaving from family, friends and the familiar environment, discrimination), the other is the formed psychological cost. ${ }^{[2]}$

So, with the increase of the size of the labor flow, the marginal cost is increasing. The main reason is that the competition between the labors is more and more intense, the time cost and the psychological loss of the flow will increase with the increase of the flow scale.

Due to the resource of labor is a resource of bleeding, and the loss of time is the largest labor cost, as flowing and to find a new job needs to spend a lot of time.

Psychological cost measurement is the most difficult. Due to institutional constraints, a large number of migrant workers to participate in the flow are difficult to achieve real sense of the flow, in the employment registration, industry of employment, social security and other aspects of discrimination, coming into the local community and enjoying the same treatment as local residents, combined with social customs and traditions outside the influence, they bear greater psychological pressure. ${ }^{[3]}$ These are the reasons for the formation of high psychological costs.

Therefore, the relationships between size of the labor flow and its marginal cost and the total cost are shown in figure 1.1: 


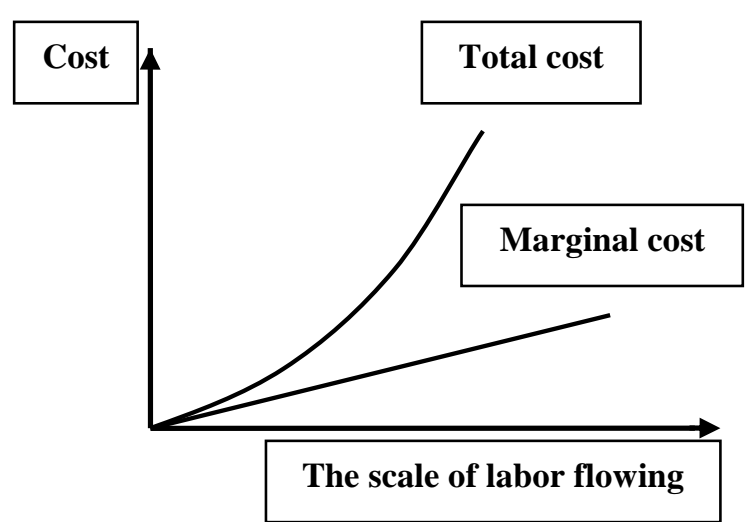

Figure 1.1 The Relationships between Sze of the Labor Fow and its Marginal Cost and the Total Cost

B. With the Increase of the Size of the Labor Flow, the Marginal Revenue is Decreasing

Compared with the total cost and marginal cost, the flow of income includes two parts, one is monetary income (such as the increase of income and the growth of additional benefits, etc.), and the other is nonmonetary income (such as a more pleasant environment, more convenient cultural facilities and health clinics, higher quality learning and training opportunities, improved social relations, personal psychological satisfaction, etc.). Generally speaking, the income of the labor flow is a kind of expected income.

However, with the increase of the size of labor flow, the marginal revenue is decreasing. Although the total income is expected to be increased (otherwise the labor force can choose not to flow), but due to the limitations of human labor capacity, the increase in income is clearly not limitless, the marginal revenue is decreasing to zero.

So, the marginal revenue and total revenue of the labor flow are be analyzed as following figure1.2.

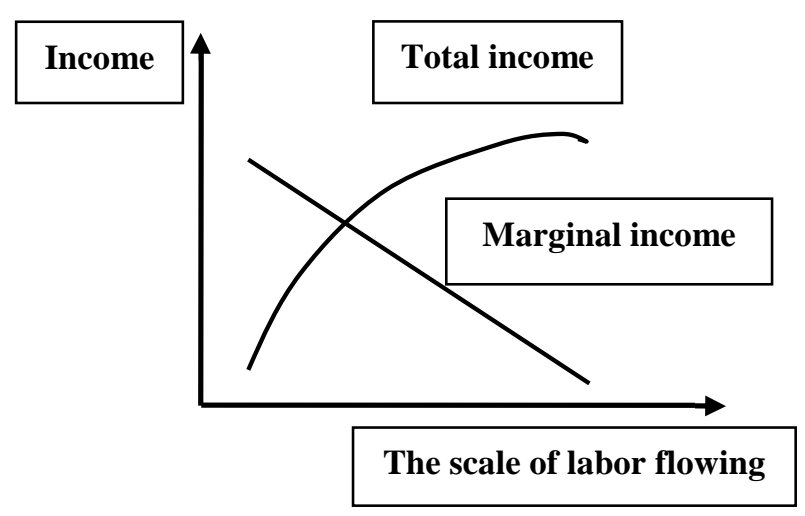

Figure 1.2 The Marginal Revenue and Total Revenue of the Labor Flow

\section{THE INFLUENCE OF LABOR COST RISE TO OUR COUNTRY'S MANUFACTURING ENTERPRISES}

Abundant labor resources and low cost and huge market potential have been the direct cause of attracting foreign capital and enterprises to invest in China, but also one of the advantages in international competition. But in recent ten years, labor, especially labor costs in urban and rural continue to rise, especially in 2005, an increase was $14 \%$, an increase of 2010 was $18 \%$, and in 2014 , it was $24 \%$, and in the next few years, labor costs still have high rising power and space. Rising labor costs will directly lead to the increase in production costs, the weakening of the price advantage will affect the competitiveness of our products in the international market; will also affect the reinvestment of foreign capital, as well as the new strategic plan of the MultiNational Corporations. And the increase of labor costs should lead to the decrease of labor demands. And the enterprise in the production cost increases, in the same time the market sale process is bearing the double pressure of the profit greatly reduces as the electric business enterprise's development.

Around 2010, a large number of manufacturing enterprises are facing the difficult choice of transformational development in China. A lot of enterprises have to abandon the production of primary products of low technology content, instead of producing the products of high quality, high-tech content and high profits goods, and at the same time, enterprises also need a large number of highly skilled, highly educated cutting-edge talent.

\section{THE ANALYSIS OF ENTERPRISE LABOR SHORTAGE}

\section{A. The Status Quo of "Labor Shortage"}

Over the past 10 years, labor intensive industries gradually showing a labor shortage situation in many areas in China, over time, this situation has not been alleviated, and even has become increasingly fierce. In the reality of recruitment, posted recruitment notices, candidates are often crowded, but few of them are eventually confirmed into the factory. In the structural contradiction of supply and demand of labor relations, we may find that there are not any workers who want to be employed, but most of them have lack of proficient, the technical bottleneck stuck in the both sides of supply and demand; and the threshold of employee training formed another obstacle. ${ }^{[5]}$

\section{B. The Nature of "Labor Shortage"}

According to the theory of new institutional economics, enterprise is the substitute of price mechanism. Labor is one kind of commodity, in the supply and demand point of view, the enterprise is willing to pay high price, all kind of goods can be bought. But companies will consider hiring labors in the equilibrium point of the social average cost and average profit. If excessive wage affects the development of the enterprises, the manufacturers would rather have employment gap than choose a recruitment quota. The new institutional economics believe that the nature of enterprise is a kind of resource allocation mechanism, which is related to the external force intervention. This kind of external force is the external cost of the enterprise or the indirect transfer, and then, leads to the development of the balance are broken.

\section{1)Cost Transfer}

Cost transfer is mainly performed in the transfer of the social costs to workers. A worker to an enterprise, considering is not only the wages, also includes a series 
of social cost (social costs, including housing, social security, sustainable development). If the social costs do not have a comparative advantage, the relative wage advantage of enterprise recruitment cannot be reflected. [6-7]

\section{2) Reform Cost Transfer}

Transformation and upgrading are the pronouns in the economic field. The gap between the East and West should not only consider the gap between the total economies, but also consider the differences in the way of economic development. ${ }^{[8]}$ The development of product upgrade and transformation leads to the sharp increase of the cost, labor shortage is not only reflected in the labor intensive industries, but also in the high-end industry development, such as environmental protection equipment, information security, aviation and gas turbine, new energy vehicles and other industries. The talent gap can only be made up by increasing wages and other ways to attract talent. There is only one way to resolve the reform of the cost of reform which is to go in the forefront of reform.

IV. HOW TO SOLVE THE PROBLEM OF ENTERPRISE LABOR SHORTAGE ON THE BASIS OF COSTS CONSTANTLY INCREASING URBAN AND RURAL LABOR MIGRATION

As there are many reasons in China's labor shortage, the thoughts of solving the problem should also be considered from many aspects, multi-pronged approach to solve the problem. In the context of increasing the cost of urban and rural labor migration, the comprehensive solution of labor shortage should be from the government, labor companies, and workers.

\section{A. The Perspective of the Government}

The government should play the role of regulation from the macroeconomic level, promote industrial structure adjustment, optimize the industrial structure, and put the employment into the primary goal of macroeconomic regulation and control. Do not to pursuit of capital intensive and technology intensive enterprise development, and rely on solely on labor-intensive enterprises. Specify the scientific and practical development plan. In addition, the government should formulate effective policies and laws on the basis of the constantly increasing labor migration cost fully to protect the legitimate rights and interests of workers are not infringed. According to the specific circumstances, adjust the minimum wage standards, to protect the living standards of the labor force and to guide the enterprise wages.

With the more serious "labor shortage" problems year by year, labor costs increase, rising raw material prices at the same time, corporate profits less and less, the burden getting heavier and heavier, quite a number of small and medium-sized enterprise are facing the survival crisis. To burden for the enterprise, supporting enterprise transformation, government should take powerful measures to give more policies to reduce the tax burden and various fees on small and medium-sized enterprises; Use tax, finance, credit policy to encourage, and support enterprise innovation, increasing the technological transformation and innovating production technology, improving operation and management, speeding up the adjustment of industry and product structure, improving labor productivity and economic benefit efficiently, so as to enhance the ability and stability enterprise to bear the "labor shortage" and reserve the constantly power of development.

To speed up the urbanization and the household registration system reform, population in large quantities from rural to urban agglomeration is the necessity of social and economic development. There is an old saying: take its heart, must keep its root. The root is the household registration, registered permanent residence. Migrant workers come into the city to work for even more than ten years, decades, but the household registration account has been in the countryside, cannot enjoy the city's social welfare, how can you peace of mind? As for this problem, the government should accelerate the process of urbanization and the household registration system reform. In the urban development planning, especially in planning new town industrial development zone, the government investment, joint investment or government and enterprises to absorb a variety of forms such as folk capital, construction of low-rent housing, economy applicable room as "apartment" of migrant workers, "apartment" new citizens, should be fully considered. Establishing relevant conditions standards, transferring limited property rights (right), and selling them to migrant workers to supply migrant workers with their own homes at the location of the job. The actions mentioned above may be the fundamental measures to solve the problem of "labor shortage" for the government.

\section{B. The Perspective of the Enterprises}

Enterprises should have a clear understanding of the characteristics of the new generation of migrant workers. According to the characteristics of the new generation of migrant workers, carry out the corresponding reform, in order to adapt to the needs of workers. There are many specific measures to develop the situation for the manufacturers, such as improving wages, improving welfare, using a performance wage to replace a fixed wage, signing with the workers legitimate labor contract, paying the five insurance payments, improving the employment ring rolled into the worker's psychological characteristics of the organization of collective activities to enrich the workers amateur cultural life. ${ }^{[9-10]}$ At the same time, in order to meet the industry development trend, labor intensive enterprises should be in the process of its transformation, to find new growth points and core competitiveness, only in order to ensure the sustainable development of enterprises, the staff in the work can be a stable development of self, to offset the growing labor migration costs. 


\section{The Perspective of the Workers}

Workers should pay more attention to their own education, cultural quality, and technology level, establish the concept of continuous learning, and constantly improve their technological level and market competitiveness. Use the law to safeguard their legitimate rights and interests, and learn to use legal weapons. In addition, they should have the spirit of struggle and hard work, through their own efforts to fight to win a better life.

\section{Integrated Strategies}

\section{1) Inland Investing}

In China's inland provinces, there is a lot of idle labor force and half the idle labor force in cities and districts of rural, urban. Idle-age labor force could become migrant workers; there is a lot of semi-idle labor force due to family, age, physical condition and other factors cannot work outside the home. If the transport conditions are guaranteed, corporate relocation to the provinces ample idle labor force, will gain greater competitive advantage of labor cost, by means of information networks, the use of local government to attract foreign capital on favorable terms, the business outlook will continue to go up.

\section{2) Changing Ideas}

Many college graduates unemployed or not is an open real employment, unemployment and cannot be in their jobs behind, not without jobs, and happens to be "from fragmentation, low not to" bring the current situation. From the social point of view of long-term trends, "blue collar top students" will inevitably become an employment trend. It's too conservative, waiting for the distant white-collar jobs, not as good as the next best thing, and a solid start from the grassroots. Moreover, a lot of entrepreneurs, mostly from the grassroots success of humble work to start, college students today and why we cannot do it step by step toward success.

\section{CONCLUSIONS}

"Labor shortage" is not a short-term phenomenon; it is not a problem the enterprises can solve easily. "Labor shortage" presents a challenge for many business management models and human resources strategy providing the workers with various question of bad environment. There is a widely accepted idea: "There is no question there is no equal opportunity" in management circles. Enterprise management level, antirisk capability, the overall strength of enterprises, and only in the process of constantly having problems, continue to solve the problem, accumulate experiences and learn lessons in order to obtain substantial growth. Therefore, "labor shortage" is not only a difficulty which is not able to be overcome, but also a rare opportunity. Take advantage of this opportunity, companies can enhance self, ahead of the competition, they may get more orders through their stable performance, and then through long-term and friendly trade relations, enjoying great reputation, corporate culture embark on the road of brand management.

\section{REFERENCES}

[1] Huo Jingming, Cost and the practice of enterprise development [N]. Tianjin: Tianjin university press, 2009(09).

[2] Yuan Ni. The economy analysis on the labor shortage and employment difficulty. [J].Reform and the strategic. 2011(01).

[3] Yang xiaomin. The economic analysis of the micro Labor shortages [N].Hubei academy of social sciences 2008(10).

[4] Smith I B. The modern theory of labor economics, and public policy (sixth edition) [M]. Beijing: people's university press.

[5] Zhang Fan. The Chinese market: The advantage of workforce [N]. In the 21st century economic report. 2010(04).

[6] China's labor market construction and labor mobility. "China's urban labor migration" team, management in the world $[\mathrm{N}]$. The 2012(04).

[7] Li Kangsi. The contemporary labor economics [M]. Beijing: Economic science press. 2012(09).

[8] Li Mingxi. Changes in the cost of urban and rural labor migration research. $[\mathrm{J}]$. economy and practice.2013. (05), pp. 8 12

[9] Wang Qicheng. Cost-benefit analysis theory. [M]. The southwest university of finance and economics press. 2009. (02)

[10] Wu Jingyu. The cost of Labour migration on the changes in the development of our country enterprise transformation. (J) Economic analysis, 2013. (09):56-57. 经济分 析. 